\title{
84. Statistical Review of Head Injuries in Children
}

\author{
Shuhei Takita, Hayami Nishijima, Yukio Sakakihara, \\ Toshiro OKano and Tsuneyo Hashimoto \\ First Department of Surgery, Tokushima University School of Medicine
}

This is a report of statistical analysis of 326 cases of head injuries in children treated in our department from 1954 through 1963.

A sharp increase in the number of indicence has been seen since 1962. As to the distribution between sexes, $67.5 \%$ were seen in male and $32.5 \%$ in female. The entire cases were classified according to ARAKI as follows:

Group 1-63.5\%, Group 2-24.5\%, Group 3-11.0\%, Group 4-1.0\% Signs and symptoms occurring in each of the grops were

$\begin{array}{lccc} & \text { Vomiting } & \text { Fever above } 38^{\circ} \mathrm{C} & \text { Convulsion } \\ \text { Group 1 } & 15.5 \% & 13.0 \% & 0.9 \% \\ \text { Group 2 } & 33.8 \% & 27.0 \% & 6.3 \% \\ \text { Group 3 } & 47.2 \% & 36.1 \% & 25.0 \% \\ \text { Group 4 } & 33.3 \% & 33.3 \% & 33.3 \%\end{array}$

Skull fractures were demonstrated in 75 cases, of which linear fracture constituted $48 \%$, depression fracture $47.4 \%$ and basilar skull fracture $3.9 \%$. Open fracture was seen in $16.7 \%$ and closed fracture was present in $83.3 \%$ of the total cases. When indicated, craniotomy was performed in 22 cases :of group 3 and 4 and hypothermia was employed in 5 cases. Intracranial themorrhage occurred in $1.0 \%$ of the total cases. Other complications of the head injuries include post-traumatic intracranial abscess, meningitis, posttraumatic epilepsy. Three deaths occurred in our series, one following removal of intracranial harpoon, one from traumatic shock and the third from cerebral contusion. One case of subdural hematoma was illustrated in 3 years old male who sustained head injury and developed headache 2 weeks later. Neurological examination was negative 50 days following the injury. A few days after the examination, the patient developed vomiting and became stuporous. Angiography revealed right subdural hematoma which was treated successfully by surgery. Attention was called to a fulminating nature of subdural hematoma in children, the onset of symptoms being quickly followed by a rapid deteriolation. 